\title{
Reverse Measurement as a Tool for Management Method Evaluation
}

\author{
Martina Tomičić Furjan ${ }^{1 *}$ \\ ${ }^{1}$ Faculty of Organization and Informatics, University of Zagreb, Pavlinska 2, Varaždin, 42000, \\ Croatia \\ *Corresponding author: Faculty of Organization and Informatics, University of Zagreb, \\ Pavlinska 2, Varaždin, 42000, Croatia. Tel: 385-42-390-828. E-mail: martina.tomicic@ foi.hr
}

Received: November 22, 2018 Accepted: July 2, 2019 Published: August 5, 2019

doi: 10.5296/erm.v5i1.15221 URL: https://doi.org/10.5296/erm.v5i1.15221

\begin{abstract}
Strategic planning is a procedure that is supposed to define organizational development through the identification of strategic goals. Models can help in understanding the business technology and in creation of formal specifications of the functionality, structure and behavior of real system appearances. By giving the entities in the model numerical values, possible improvements can be simulated, measured and evaluated according to the measurements, and then use for managing the organization. The issue on this approach is that the results that are gotten from the model measurements can be compared to the real values that the model results represent only after they are already accomplished. In this paper the use of reverse measurement is being introduced as a tool for evaluating management methods, in order to ensure the usability of a method prior to its application for managing the organization.
\end{abstract}

Keywords: Management methods, Performance measurement, Evaluation 


\section{Introduction}

Achievement of strategic goals requires the use of significant resources of an organization. Strategic goals, as a result of the process of strategic planning, defined by Bryson (Bryson, 2011) as "deliberative, disciplined approach to producing fundamental decisions and actions that shape and guide what an organization (or other entity) is, what it does, and why", are supposed to give a vision of an organization in the future. Strategic planning as a management tool has appeared in the mid-1960s, and leaders in companies started to accept it as "the best way to devise and implement strategies that would enhance the competitiveness of each business unit" (Mintzberg, 1994). This way of planning and managing was successful during the time when the changes in organization's environment occurred relatively rarely. However, with the fast development of science and technology, and with transiting from the industry age to the information age in the mid-1980s, and to digital age nowadays, enterprises are faced with the extensively increased frequency of changes, and traditional strategic planning is not appropriate anymore to maintain the competitiveness of the organization. By definition, the strategic planning process includes the performance of the following five steps: (1) selecting the corporate mission and major corporate goals, (2) analyzing the external competitive environment, (3) analyzing the internal operating environment, (4) selecting appropriate organizational strategies and (5) implementing the selected strategies (Hill \& Jones, 2008).

Thereby, organizations need to anticipate and adjust to environmental trends that effect their industry (Hassan \& Galal-Edeen, 2017).

In order to move towards the achievement of the defined strategic goals, all organizational activities and their operative goals have to be oriented towards them. Since this is a complex process that should include all employees of the organization, the activities and efforts must be managed and lead, meaning that a management method has to be introduced and implemented. Although the implementation of new methods is supposed to bring benefits to the organization, new procedures are also always risky, and it is never sure if they will bring the desired results and lead the organization where it wants to be.

Generally, there are two risk management problems organizations are facing: firstly, to get managers to undertake risk management actions which are in the best interest of the organization and its investors, and secondly, to collect information about risk situations in a timely, intelligible and relevant format (Jankensgård, 2019). In implementation of risk management culture in organizations, identifying the most relevant critical success factors can help, since the implementation of involves different variables, such as: people, culture, processes, technologies, and management strategies (Oliveira et al., 2019). Thereby risk management includes governance and management control concepts, which that are hard to investigate by using only statistical and deductive methods (McShane, 2018).

Reverse measurement, which is going to be introduced in this paper, is a tool that gives the possibility of "going back" to the past, simulating the improvements on "old" data as input values and comparing them to old real values. If the results are better in the simulation then in real life, the management method is good and can be used for getting advantage of it in 
managing the organization, if they are not better, then the management method should be changed. By management method we understand here the way of ensuring that the defined activities are performed, and the goals are achieved.

The structure of the paper is as follows. After the introduction, a short overview of the literature regarding models, management method evaluation and the use of measurement tools for the evaluation, as its subset, is given, as well as the research methodology is described. The next part of the paper describes how to use reverse measurement for management method evaluation with help of models, followed by discussion including the limitations of this research. At the end of the paper, a short conclusion is given and plans for future work.

\section{Background and Research Methodology}

Strategic planning is a "disciplined effort to make basic decisions and implement activities inside the organization, which answer these questions: What is the organization? What does it do? Why does it do it?"(Bryson \& Alston, 2010). When the strategic goals are defined, their accomplishment is ensured by performing activities that lead the organization in the defined direction.

Management methods help managers in decision making, improvement of efficiency and effectiveness and in planning and control (Armstrong, 2006). In order to evaluate the improvement, a performance measurement method can be used. Financial indicators were mainly in the focus of performance measurement until the early 1990-ties. Since then a number of performance measurement methods have been developed and between 1990 and 2011 there was a revolution of performance measurement frameworks and methods development, which led to a change in the nature of work (Yadav \& Sushil Sagar, 2013).

Performance measurement in an organization allows tracking of the development of strategic initiatives and helps to evaluate the achievement of desired results by a range of management activities, such as monitoring and reporting, budgeting and finance management, program management, processes, communication etc. (Poister, 2003). There are many reasons why organizations measure effectiveness, but they can all be classified into one of the three groups: Controlling behavior, External reporting and compliance and Learning and empowerment (Marr, 2009). Only the third reason brings benefit to the organization when implementing any performance measurement method. Measuring organizational performance can help to audit the realization of all the activities that lead to achievement of the goals through defined periods of time, while without its application the procedure of following the achievement of goals is reduced to the study of statistical data which for some activities exist and for some cannot be identified.

Deeper research of the research topic reviewed available literature on evaluation of management methods in order to summarize findings in this research field. The focus has been put on the methodologies published in scientific publications in the subject area of business management and accounting and in social sciences. Relevant database that was selected is Scopus. The search was conducted based on the combination of keywords 


\section{Macrothink}

"evaluation" and "management method". The search was conducted in October 2018 for the time period of the last 20 years $(1998$ - 2018) and it received results containing 144 hits in Scopus. The results (depicted in Figure 1) show that although the terms were used in all the selected years, the highest number of publications were published in 2011 and in 2017.

Documents by year

Scopus

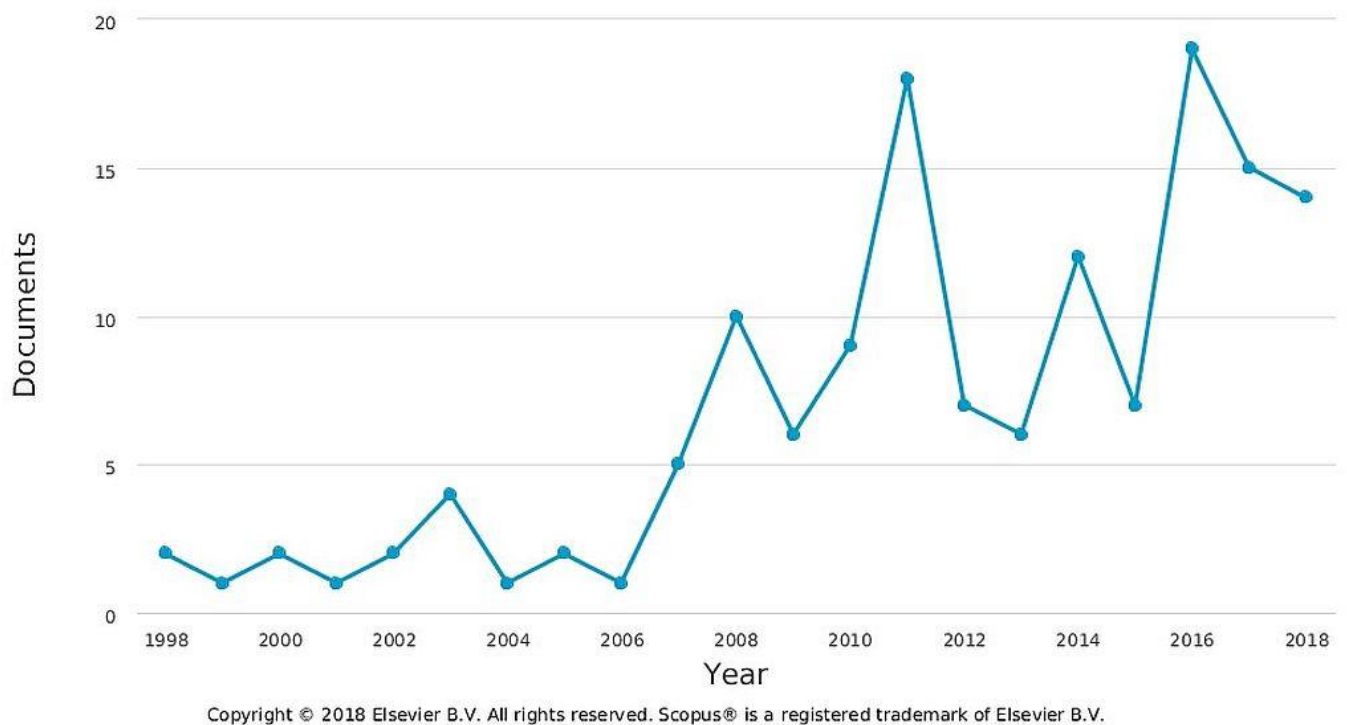

Figure 1. Evaluation of Management Methods Publication by Year of Publication (SCOPUS)

For a more detailed topic research the analysis was refined using the term "performance measurement", in order to connect the use of performance measurement methods to evaluation. The refined analysis (Figure 2) resulted with only 17 hits, showing little use of those methods in analysis.

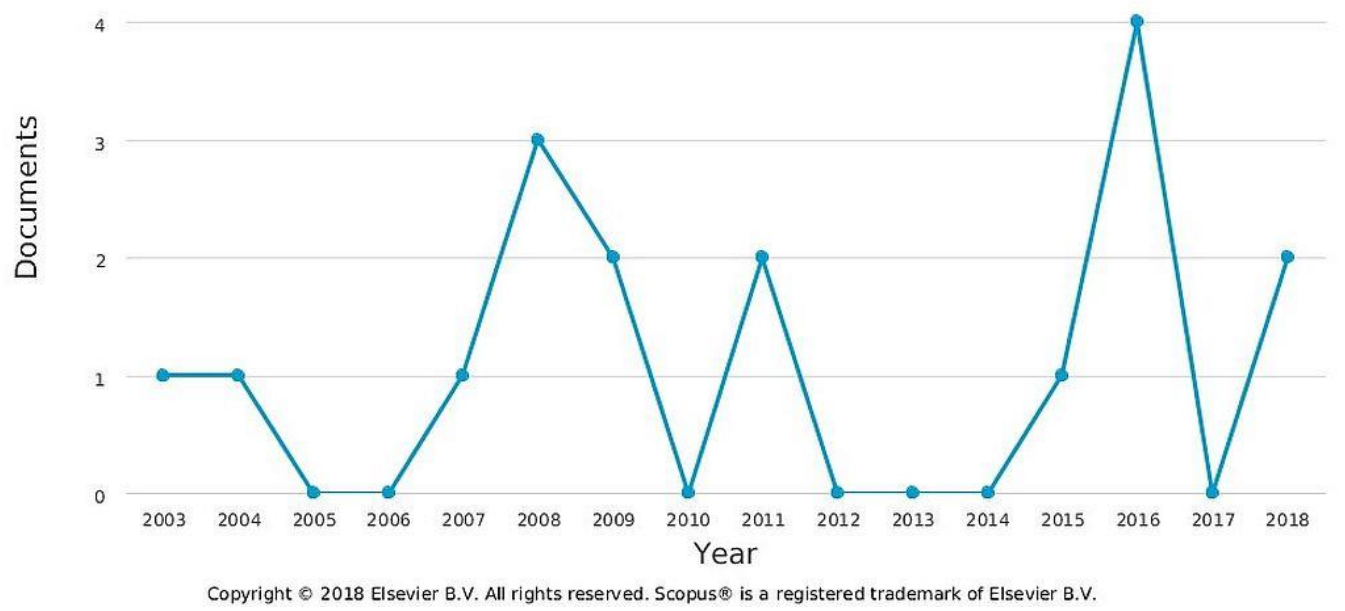

Figure 2. Evaluation of Management Methods and Performance Publication by Year of Publication (SCOPUS) 


\section{Macrothink Institute ${ }^{\mathrm{TM}}$}

The short insights include limited literature insights in only one high-quality database. Due to that fact, this literature review cannot be considered as comprehensive, but it shows indications that the number of publications about the evaluation of management methods has grown in the past few years, but it is not widely used, which is an indicator that the field is worth of research. Further research in this field could investigate types of publications and the more detailed report on case studies about evaluation of management methods.

Strategic and operative planning of an organization result with strategic and operative goals and activities directed towards the achievement of the defined goals. Since the process of planning and the implementation of the plan is complex, a method for managing it must be introduced and used.

The level of achievement of the defined goals can be evaluated by using a performance measurement method, that by determining the values of measures evaluates the management method as well. A model can help in formalizing the measurement method. Models can help in understanding the business technology and in creation of formal specifications of the functionality, structure and behavior of real system appearances, which in organizations mean that they can help in understanding how the work is done and how it can be improved. Modelling is the process of creating an abstract representation of a system. The model, as the outcome of the modelling process, is the result of the abstraction process that reflects the features of a system and represents a formal specification of the functionality, structure and behavior of the system (Raffai, 2008).

Figure 3 shows the described relation of management method and its evaluation.

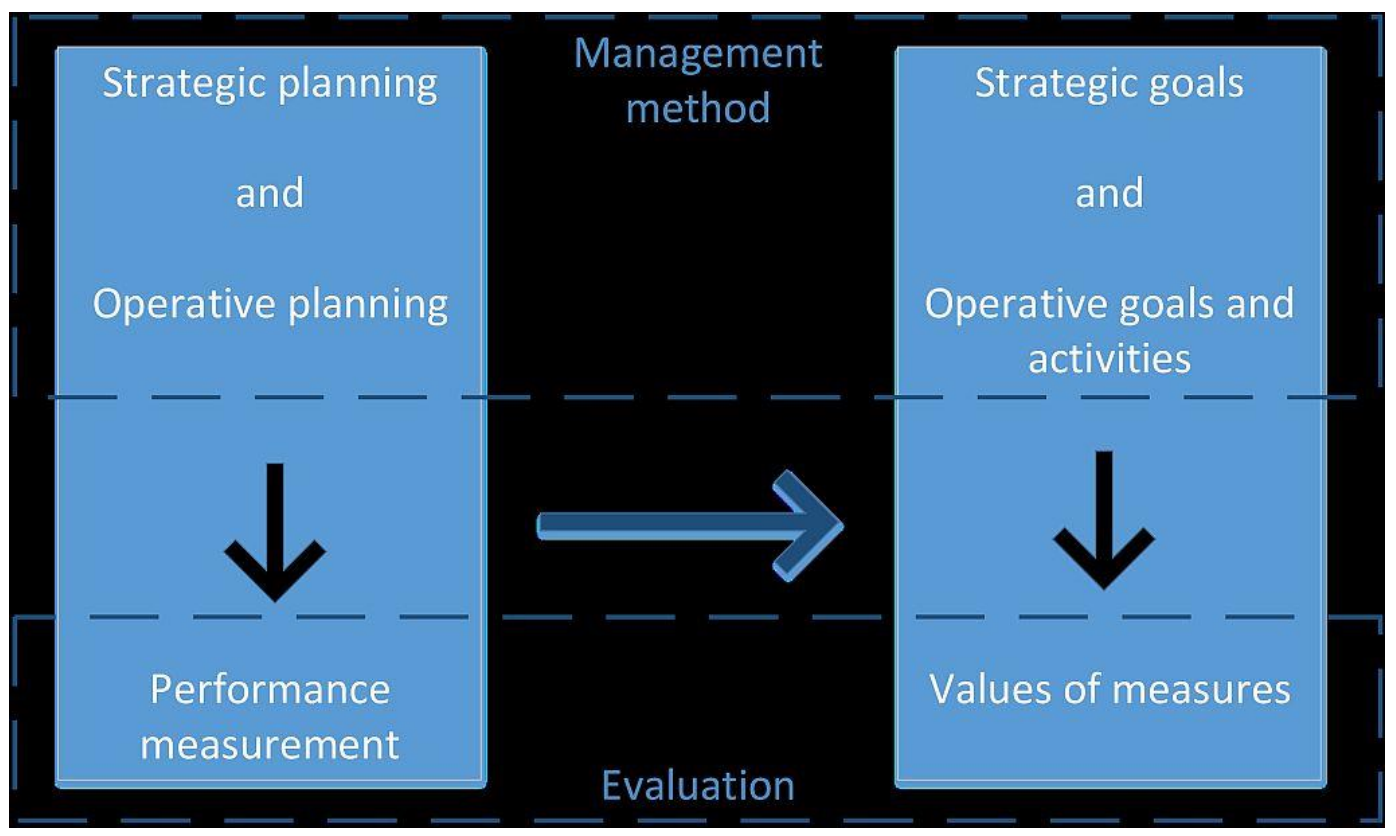

Figure 3. Relation of Management Method and Its Evaluation 
Evaluation of the used management method is usually made after a certain period of time, when results that are gotten from the measurements can be compared to the real values that the results represent.

\section{Reverse Measurement as a Tool for Evaluation}

Reverse measurement, as a tool for evaluation of the management method prior to its implementation, uses "old" real-life data as start values, simulates the activities that were derived from the planning process and measures their results for a defined number of periods. The end results for every defined period are compared with the real-life values for the same measures and same periods. If the results are better in the simulation then in real life, the management method is good, if they are not better, then the management method has to be changed.

The implementation of reverse measurement is shown in figure 4 and includes the following steps:

1. Determine the time periods for the comparison to be carried out - Planning and managing period (PMP) 1 to $\mathrm{n}$, whereby PMP1 is the starting period for evaluation in the past.

2. Identify sets of activities defined by the current management method in the corresponding PMP, that transform the real start values $(\mathrm{X})$ to the real accomplished values $(\mathrm{Y})$.

3. Consider how to gather $\mathrm{X}$ and $\mathrm{Y}$ (possible ways include data from existing Information system or data from strategic or reporting documents) and determine them.

4. Simulate sets of activities defined by the new management method, using the same real start values $(X)$ in order to transform them into the new accomplished values $(Z)$. Formal activities are functions where $\mathrm{X}$ becomes $\mathrm{Y}$ and where $\mathrm{X}$ becomes $\mathrm{Z}$.

$$
\begin{aligned}
& \text { 1. } \mathrm{APMPn}=\{\mathrm{A} 1(\mathrm{X} 1, \mathrm{Y} 1), \mathrm{A} 2(\mathrm{X} 2, \mathrm{Y} 2), \ldots, \mathrm{Am}(\mathrm{Xm}, \mathrm{Ym})\} \\
& \text { 2. } \mathrm{NAPMPn}=\{\mathrm{A} 1(\mathrm{X} 1, \mathrm{Z} 1), \mathrm{A} 2(\mathrm{X} 2, \mathrm{Z} 2), \ldots, \mathrm{Am}(\mathrm{Xm}, \mathrm{Zm})\}
\end{aligned}
$$

5. The qualitative analysis compares the activities for the $\mathrm{n}$ planning and management periods (PMP1 ... n). Activities from the current management method can be equal / or partially or completely different $(\mathrm{A}(\mathrm{X}, \mathrm{Y}))$ for individual periods, while activities from the new management method $(\mathrm{A}(\mathrm{X}, \mathrm{Z})$ ) change only in the event of a change in the goals from which they arise.

6. The quantitative analysis compares the actual realized values (PMP1 $(\mathrm{Y} 1 \ldots \mathrm{m}) \ldots \mathrm{n})$ that are the result of the implementation of APMP1 ... n on the start values (PMP1 (X1 ... $\mathrm{m}) \ldots \mathrm{n})$ with values accomplished in simulation (PMP1 $(\mathrm{Z} 1 \ldots \mathrm{m}) \ldots \mathrm{n})$ as the result of the implementation of NAPMP1 ... n on the same start values (PMP1 $(\mathrm{X} 1 \ldots \mathrm{m}) \ldots \mathrm{n})$. 


\section{1) Macrothink}

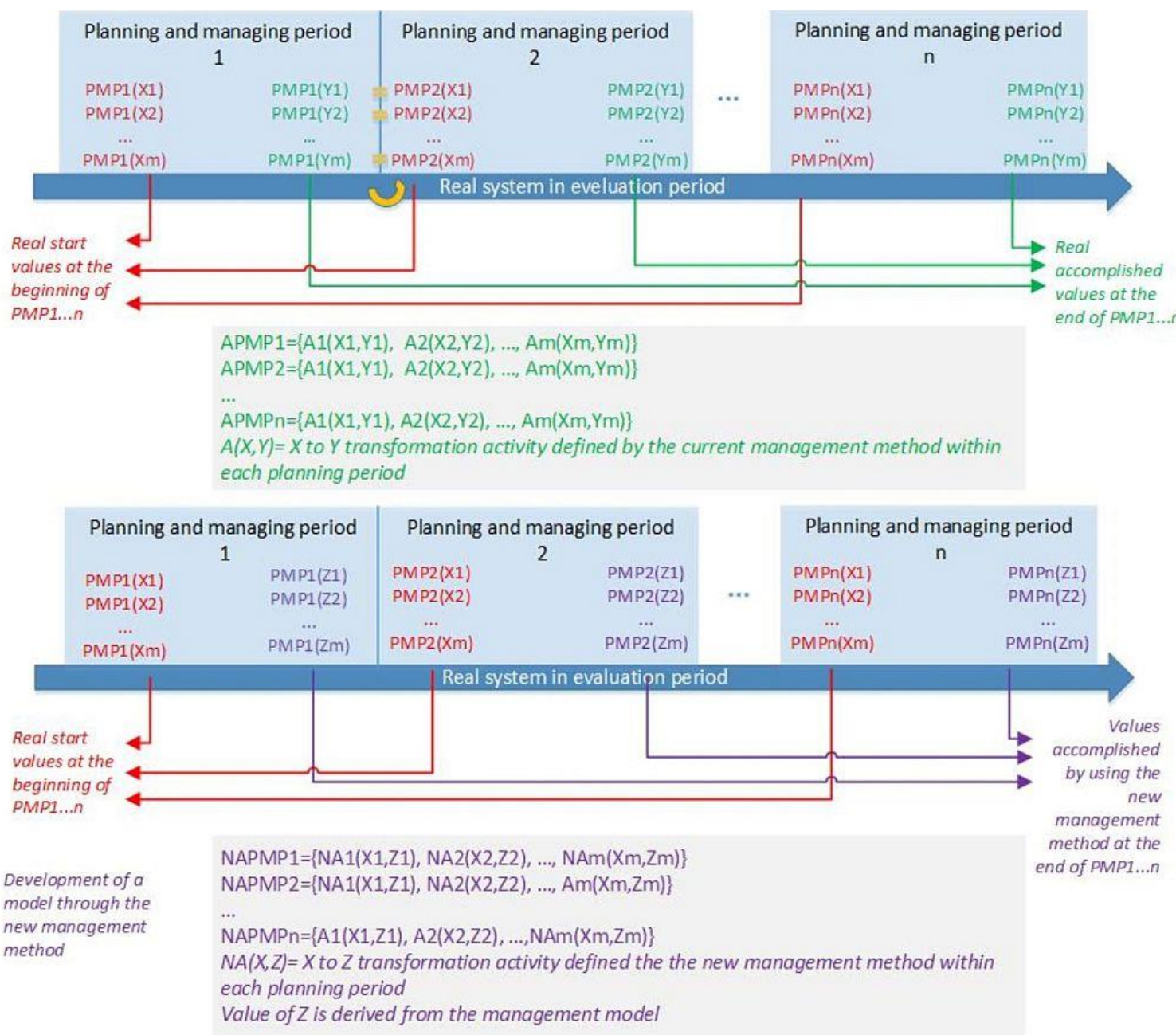

Figure 4. Reverse Measurement Implementation for Management Method Evaluation

\section{Discussion}

In the previous chapter an outline is given on how to use reverse measurement for comparing values without an appropriate management method and values of defined measures when a new management method is implemented.

The new management method in this paper relates to performance measurement. Since strategic planning of enterprise development is a long-term process, but it is usually performed in cycles, it results with defined strategic goals, which should be achieved in a certain period of time. The measurement of the achievement of the defined strategic goals ensures that the plan is accurate and that it is upgraded and adapted to new circumstances that occur both internally, within the organization and its everyday work, as well as in its environment.

Several observing can be drawn from the defined comparison process:

1. There can and should be a semantic similarity of the activities obtained by analysis of the strategic goal and the implementation of strategic planning in the past. 
2. The values of measures that measure the achievement of goals of implemented or planned activities using a performance measurement method are easier and more precise to be determined (since they are planned that way) than by analyzing the organization's strategic documents. Moreover, some of the values of the measures are in the second case are impossible to determine, since they are either not recorded or are impossible to distinguish from other measures.

3. By applying a performance measurement method for measuring organizational effectiveness and risk management, it is possible to identify the influence of the values of the measures of the realized goals on the achievement of the strategic goal, while this cannot be identified for the achievement of the strategic goal according to the strategic documents.

4. Using a performance measurement method, it is possible to monitor the realization of all activities that lead to the achievement of a strategic goal, and the achievement of the strategic goal itself, while without applying it, the process is reduced to the study of statistics, which for some activities exist, and for some are not identifiable.

\section{Conclusion}

The application of the performance measurement enables monitoring of the development of an organization from the strategic planning stage to the realization of all necessary activities to move from the present state to the future, desired state. In order to achieve the strategic goals successfully, it is necessary to provide timely information on the degree of their realization or realization of certain activities in the achievement of each strategic goal. In that way the resources of the organization can be effectively managed. In order to use the information, a model that collects and stores the information has to be implemented. If we want to evaluate if the activities are defined well at the beginning, reverse measurement can be applied. Reverse measurement is a special and novel approach to the evaluation, which with use of historical data gives an outlook on the management method usability in the future.

Although this work gives a proposal of a new approach to evaluation of management methods used in organizations, it also has some limitations. For performing the steps in the proposed methodology, some semantically similar activities from the current management method and from the new management method must be identified. The values of measures that measure the goals defined by the process of strategic planning for the future are simpler and more precise to be determined through a model than the values of measures determined from the current IS or by analyzing organization's strategic documents. Moreover, some of the values of the later mentioned measures are impossible to determine, they are not kept in the records or it is impossible to separate them from values of other measures.

Using the proposed approach also doesn't take into account the organizational external environment with changing conditions and trends, as well as changes that occur every day inside of an organization. If some activities and effort are positively evaluated in the past, does not mean that they would work well today or tomorrow. Therefore, the proposed tool for 
evaluation can be used only as an orientation and give general information and not exact data.

\section{References}

Armstrong M. (2006). A Handbook of Management Techniques: A Comprehensive Guide to Achieving Managerial Excellence and Improved Decision Making. UK: Kogan Page.

Bryson J. M., \& Alston F. K. (2010). Creating and Implementing Your Strategic Plan. USA: John Wiley \& Sons.

Bryson J. M. (2011). Strategic planning for public and nonprofit organizations: A guide to strengthening and sustaining organizational achievement. USA: John Wiley \& Sons.

Hassan, H. A., \& Galal-Edeen, G. H. (2018). A Business Enterprise Resilience Model to Address Strategic Disruptions. Enterprise Risk Management, 4(1), 15-34. https://doi.org/10.5296/erm.v4i1.13715

Hill, C. W., \& Jones, G. R. (2008). Strategic management: an integrated approach. USA: Cengage Learning.

Jankensgård, H. (2019). A theory of enterprise risk management. Corporate Governance International Journal of Business in Society. https://doi.org/10.1108/CG-02-2018-0092

Marr B. (2009). Managing and delivering performance. UK: Elsevier. https://doi.org/10.4324/9780080943015

McShane, M. (2018). Enterprise risk management: history and a design-science proposal. The Journal of Risk Finance. https://doi.org/10.1108/JRF-03-2017-0048

Mintzberg, H. (1994). The fall and rise of strategic planning. USA: Harvard Business Review.

Oliveira, K., Méxas, M., Meiriño M., \& Drumond, G. (2019). Critical success factors associated with the implementation of enterprise risk management. Journal of Risk Research, 22(8), 1004-1019. https://doi.org/10.1080/13669877.2018.1437061

Poister T. H. (2003). Measuring performance in public and nonprofit organizations. USA: Jossey-Bass Publishers.

Raffai M. (2008). Model oriented enterprise integration: Metamodel for realizing the integration. Springer. https://doi.org/10.1007/978-0-387-76312-5_1

Yadav N., \& Sushil Sagar M. (2013). Performance measurement and management frameworks: Research trends of the last two decades. Business Process Management Journal, 19(6), 947-970. https://doi.org/10.1108/BPMJ-01-2013-0003 


\section{Copyright Disclaimer}

Copyright for this article is retained by the author(s), with first publication rights granted to the journal.

This is an open-access article distributed under the terms and conditions of the Creative Commons Attribution license (http://creativecommons.org/licenses/by/3.0/). 